Check for updates

Cite this: J. Mater. Chem. C, 2017, 5, 7969

Received 28th April 2017, Accepted 26th June 2017 DOI: $10.1039 / c 7 t c 01853 c$

rsc.li/materials-c

\title{
Fluoride-sulfophosphate glasses as hosts for broadband optical amplification through transition metal activators $\dagger$
}

\author{
W. C. Wang, ${ }^{a b}$ Q. H. Le, ${ }^{a}$ Q. Y. Zhang (D) ${ }^{b}$ and L. Wondraczek (D) *a
}

\begin{abstract}
Unusually stable multi-anion glasses of the fluoride-sulfophosphate type (FPS) are introduced as a new host material for optically active cation species. Despite a notoriously low polymerization grade, anion mixing in this glass system enables facile manufacture of bulk or fiber devices which combine several advantages of fluoride and phosphate glasses while using the stabilizing effect of sulfate additions. Using the example of chromium doping, we demonstrate broad red photoluminescence at $734 \mathrm{~nm}$ and inhomogeneous broadening of the $R$-line at $694 \mathrm{~nm}$, originating from the ${ }^{4} \mathrm{~T}_{2} \rightarrow{ }^{4} \mathrm{~A}_{2}$ and ${ }^{2} \mathrm{E} \rightarrow{ }^{4} \mathrm{~A}_{2}$ transitions of $\mathrm{Cr}^{3+}$, respectively. The luminescence mechanism is further analyzed on the basis of the corresponding Tanabe-Sugano diagram. Tailored through chemical composition, internally nucleated precipitation of a nanocrystalline fluoride phase enables switching between high-field and low-field configurations of the $\mathrm{Cr}^{3+}$ ion, resulting in the specific emission properties and setting the path towards FPS-based optical devices.
\end{abstract}

\section{Introduction}

Transition metal doped glasses have been receiving continuous attention in the quest for new tunable fiber lasers. ${ }^{1,2}$ In particular, different chromium ions have been considered as interesting species, taking into account their prominent role in crystalline laser gain media, e.g., $\mathrm{Cr}^{3+}$ in ruby lasers, ${ }^{3} \mathrm{Cr}^{4+}$ in YAG and forsterite, ${ }^{4}$ or $\mathrm{Cr}^{2+}$ in the chalcogenide matrix. ${ }^{5}$ While chromium ions occur in a broad variety of valence states (ranging from " +1 " to " +6 "), in oxide glasses, only $\mathrm{Cr}^{3+}, \mathrm{Cr}^{5+}$ and $\mathrm{Cr}^{6+}$ are typically found. ${ }^{6-8}$ of particular interest are the broad near-infrared emission bands and the narrow visible emission bands which derive from the ${ }^{4} \mathrm{~T}_{2}$ level (low-field sites) and the ${ }^{2} \mathrm{E}$ level (high-field sites) of $\mathrm{Cr}^{3+}$, respectively. Their energetic position is dominated by the ligand-dependence of the underlying $d-d$ transition. ${ }^{9-11}$ Broadband emission at approximately $900 \mathrm{~nm}$, originating from $\mathrm{Cr}^{3+}$ ions in a phosphate glass matrix, was reported by Sharp et al. as early as $1969 .{ }^{12}$ Since then, many authors have been considering the subject. For example, Murata et al. provided a systematic study on the relationship of composition and redox reactions among chromium ions in multicomponent oxide

${ }^{a}$ Otto Schott Institute of Materials Research, Friedrich Schiller University Jena, Fraunhoferstraße 6, 07743 Jena, Germany. E-mail: lothar.wondraczek@uni-jena.de ${ }^{b}$ State Key Laboratory of Luminescent Materials and Devices, Guangdong Provincial Key Laboratory of Fiber Laser Materials and Applied Techniques, and Institute of Optical Communication Materials, South China University of Technology, Guangzhou 510641, P. R. China

$\dagger$ Electronic supplementary information (ESI) available. See DOI: 10.1039/c7tc01853c glasses, reporting a redox shift from $\mathrm{Cr}^{3+}$ to $\mathrm{Cr}^{6+}$ with increasing matrix basicity. ${ }^{13}$ Also in the form of optical fibers, significant progress has been made. For example, $\mathrm{Cr}^{3+}$-doped silica fibers with a gain bandwidth covering the entire transmission range of low loss and low dispersion windows were reported in 2012, aimed at increasing the data transmission capacity in the next generation of optical communication systems. ${ }^{14} \mathrm{Cr}^{3+}$-doped glass ceramic fibers were also demonstrated for potential application in broadband tunable fiber lasers. ${ }^{15}$ However, despite these milestone findings, the preparation of efficient fiber lasers from a $\mathrm{Cr}^{3+}$-doped glass has not yet been successful. Therefore, the search for suitable host materials continues.

Traditionally, phosphate glasses have been among the most prominent choices as host species for solid-state (glass) lasers, primarily due to high rare earth solubility and low phonon energy. ${ }^{16-18}$ The structural backbone of these materials comprises a network of $\mathrm{PO}_{4}$ tetrahedra in which three of the oxygen species provide the ability to link to a neighboring tetrahedron, while the remaining anion is linked to the central phosphorous via a double bond. This configuration is the fundamental basis for the specific optical properties of phosphate glasses, in particular, electronic polarizability. Secondary cation species (including rare earth or transition metal ions) can be added to this ensemble as so-called modifiers, that is, introducing chemical bonds with a more ionic character. Then, in order to charge-balance these modifier ions, not all three available edges of the phosphate tetrahedron are interconnecting, but non-bridging oxygen species are formed which interrupt the 
phosphate network. This is expressed in the $Q$-group nomenclature, where $Q^{n=0 \ldots 3}$ refers to a phosphate entity with $n$ bridging oxygen species. If $n=2$ (the metaphosphate composition), the network comprises phosphate chains and/or rings. For $n>2$ (ultraphosphates), these chains are crosslinked. When $n=0 \ldots 1$ (pyro-/orthophosphates), the glass comprises isolated phosphate islands in an ionic matrix. The modifying species locate between the super-structural units. Depending on charge, size and electronic structure, they interact with the local phosphate network to a different extent. Furthermore, non-linear cross-interaction among the cations leads to specific mixing effects, which are frequently made use of in the design of certain macroscopic properties. ${ }^{19-21}$ It was found that the stability of phosphate glasses can be enhanced significantly through the introduction of sulfate anions, $\left[\mathrm{SO}_{4}\right]^{2-}$, both in terms of rheology (liquid fragility) and chemical properties (corrosion resistance). ${ }^{22-24}$ Beyond this immediate, practical interest, these sulfophosphate glasses have also been identified as interesting host species for transition metal ions as they provide a very peculiar local environment of sulfate as well as phosphate entities in which ligand field splitting and local redox deviate from conventional molecular field considerations. ${ }^{23,25}$ However, especially at high sulfate content, liquid-liquid phase separation has been observed, which prevents their use as fiber or bulk optical materials. ${ }^{26}$

In the present study, this leads to further extension of this chemical system by adding fluoride as another structural entity, creating fluoride-sulfophosphate glasses (FPS). As a well-known counterpart, fluorophosphate (FP) glasses combine many properties which are desired in high-performance optical applications, e.g., high optical transmittance across the ultraviolet (UV) to near-infrared (NIR) spectral range, very low partial dispersion and linear and non-linear refractive index ${ }^{27}$ (thus, high laser damage threshold), low phonon energy and the ability of incorporating large amounts of optically active species, based on the chemical and electrical properties of the fluoride anion relative to those of oxygen. Applications have been evolving on the basis of these properties primarily on the areas of (passive) optical lenses, fiber optical amplifiers, lasers and frequency converters, ${ }^{28,30}$ with current research focusing on the effects of mixed doping with various rare earth species, ${ }^{31}$ and also on modifying the glass matrix through the addition of further anion species. $^{27,32,33}$ For example, Kumar et al. studied the effect of sulfate and borate additions on the optical properties of FP glasses, reporting that sulfate acts positively on luminescence efficiency of rare earth dopants. ${ }^{34,35}$ Important in these considerations, when the introduction of new anion species leads to an improvement of thermal stability or, e.g., mechanical performance, it must not adversely affect the spectroscopic properties of the dopant species. With this in mind, FPS glasses provide an extremely complex structural environment to optically active dopant species and, according to recent findings, ${ }^{36}$ surprising glass stability and a broad processing window. Here, we exploit these properties in a new host material for chromium-based broadband optical activity. We compare a series of $\mathrm{Cr}^{3+}$-doped FPS glasses to their sulfate-free FP counterparts with varying $\mathrm{F}: \mathrm{P}: \mathrm{S}$ and $\mathrm{F}: \mathrm{P}$ ratios, respectively, by means of assessing their structural and optical properties. This shows that FPS glasses provide a promising material towards broadband tunable fiber lasers.

\section{Experimental}

Two sets of glasses were considered in the present study, i.e., a fluoride sulfophosphate (FPS) and a reference fluorophosphate (FP) series. Molar compositions were selected by starting from alkaline earth FP, $(100-x)\left(\mathrm{MgF}_{2}, \mathrm{CaF}_{2}, \mathrm{SrF}_{2}, \mathrm{AlF}_{3}\right)-$ $x \mathrm{Sr}\left(\mathrm{PO}_{3}\right)_{2}(x=0,2,4,10,15$; denoted FP0, FP2, FP4, FP10, and FP15, respectively), ${ }^{27-29}$ and subsequently replacing $\mathrm{Sr}\left(\mathrm{PO}_{3}\right)_{2}$ in the FP15 composition by $\mathrm{SrSO}_{4}, 85\left(\mathrm{MgF}_{2}, \mathrm{CaF}_{2}, \mathrm{SrF}_{2}, \mathrm{AlF}_{3}\right)-$ $(15-y) \operatorname{Sr}\left(\mathrm{PO}_{3}\right)_{2}-y \mathrm{SrSO}_{4}(y=5,7.5,10,15$; denoted as FP10S5, FP7.5S7.5, FP5S10, and FP0S15, respectively). All glasses were doped by adding $0.05 \mathrm{~mol} \% \mathrm{Cr}_{2} \mathrm{O}_{3}$. Only $\mathrm{Sr}\left(\mathrm{PO}_{3}\right)_{2}$ was dried at $120{ }^{\circ} \mathrm{C}$ for $7 \mathrm{~h}$ before weighting, then $100 \mathrm{~g}$ batches using high purity raw materials were thoroughly mixed in a plastic bottle. Batches of $100 \mathrm{~g}$ were melted in a muffle furnace, in $\mathrm{Pt}$ crucibles at $1000-1100{ }^{\circ} \mathrm{C}$ for $2 \mathrm{~h}$, cooled to $830-950{ }^{\circ} \mathrm{C}$ and poured into a preheated graphite mold. The subsequent annealing process was carried out at $440-510{ }^{\circ} \mathrm{C}$ for another $2 \mathrm{~h}$, followed by cooling to room temperature at the furnace rate $\left(\sim 2 \mathrm{~K} \mathrm{~min}^{-1}\right)$. Deviating from this procedure, the compositions with poor glass forming ability (FP0, FP2, FP5S10 and FP0S15) were prepared through rapid quenching by pouring the melt onto cold copper plates and immediate pressing with another copper stamp. Subsequently, annealing of these samples followed the same procedure as above. After annealing, the glass samples which were obtained through the regular method were cut into two types of specimens, i.e., $20 \mathrm{~mm} \times 10 \mathrm{~mm} \times 1 \mathrm{~mm}$ and $20 \mathrm{~mm} \times 10 \mathrm{~mm} \times 5 \mathrm{~mm}$, and both sides were polished for further spectroscopic analyses and mechanical analyses, respectively. For the quenched samples of FP2 and FP5S10, the obtained plates were polished directly without further cutting. In the case of FP0 and FP0S15, polishing was not possible because the samples were too thin $(0.5-0.6 \mathrm{~mm})$, so that spectroscopic analyses were performed directly on unpolished samples. Remaining glass shards were ground and sieved for differential thermal analysis (DTA) and X-ray diffraction (XRD) analysis.

The glass density was tested through the Archimedes method at $20.5{ }^{\circ} \mathrm{C}$ using distilled water as the immersion liquid. XRD was conducted on a MiniFlex600 (Rigaku, Japan) X-ray diffractometer with $\mathrm{Cu}-\mathrm{K} \alpha$ radiation $(\lambda=1.5406 \AA)$ at a tube voltage of $40 \mathrm{kV}$ and a tube current of $15 \mathrm{~mA}$. The glass refractive index was evaluated with a Pulfrich refractometer on samples with a thickness of $5 \mathrm{~mm}$. UV-Vis-NIR absorption spectra were recorded on a Cary 5000 (Agilent) double-beam spectrophotometer with a spectral resolution of $1.0 \mathrm{~nm}$. The glass transition and characteristic temperatures of crystallization were analyzed on a Differential Thermal Analyzer instrument assembled by our laboratory. Structural analyses were done by Raman spectroscopy (Renishaw, UK) using a $488 \mathrm{~nm}$ Argon laser as the excitation source. Static luminescence spectra were recorded on a high-resolution spectrofluorometer (Fluorolog, Horiba Jobin-Yvon), using a continuous 
wave $450 \mathrm{~W}$ Xe lamp as the excitation source and a Hamamatsu R2658P photomultiplier tube for detection.

Finally, the elastic properties were characterized by ultrasonic echography on co-planar, optically polished glass plates. The longitudinal and transversal wave velocities, $c_{\mathrm{L}}$ and $c_{\mathrm{T}}$, were determined with a piezoelectric transducer operating at frequencies of 8-12 MHz (Echometer 1077, Karl Deutsch GmbH \& Co KG).

All measurements were performed at room temperature.

\section{Results and discussion}

\subsection{Glass formation, optical absorption and basic physical properties}

As noted in the Experimental section, with the exception of the low- or no-phosphate candidates, all compositions were readily cooled into visually transparent glasses without visible bubbles, inclusions or signs of crystallization. Sample photographs are provided in the inset of Fig. 1. As expected, $\mathrm{Cr}^{3+}$-doping resulted in a green tint with increasing saturation for increasing phosphate content. For FP2 and FP5S10, the green appearance evolves into a light yellowish shade, and turns to red for FP0 and FP0S15. In the latter two samples, some turbidity is seen, indicating that these samples comprise at least two phases. The red color is similar to that of ruby, where it is caused by $\mathrm{Cr}^{3+}$ in the alkali matrix $\alpha-\mathrm{Al}_{2} \mathrm{O}_{3}$, in a strained six-fold coordination. ${ }^{37}$ This implies that also in the present case, $\mathrm{Cr}^{3+}$ ions enter into the strong ligand field of a crystalline precipitate. ${ }^{38,39}$ Fig. 1 shows the UV-NIR absorption spectra which correspond to the above observations. In the regularly cast samples, there are two broad absorption bands, i.e., at $439 \mathrm{~nm}$ and $640 \mathrm{~nm}$, associated with the characteristic $\mathrm{Cr}^{3+}:{ }^{4} \mathrm{~A}_{2} \rightarrow{ }^{4} \mathrm{~T}_{1}$ and $\mathrm{Cr}^{3+}:{ }^{4} \mathrm{~A}_{2} \rightarrow{ }^{4} \mathrm{~T}_{2}$ transitions. A zoom at the red region reveals two distinct shoulder bands at $\sim 647 \mathrm{~nm}$ and $680 \mathrm{~nm}$, corresponding to $\mathrm{Cr}^{3+}:{ }^{2} \mathrm{~T}_{1} \rightarrow{ }^{4} \mathrm{~A}_{2}$ and $\mathrm{Cr}^{3+}:{ }^{4} \mathrm{~A}_{2} \rightarrow{ }^{2} \mathrm{E}$ (see Fig. S1 in the ESI $\dagger$ ). In addition to this, a further intense absorption band is observed at $\sim 251 \mathrm{~nm}$, attributed to the charge transfer state of $\mathrm{Cr}^{6+}$, indicating a strongly oxidizing effect in the quenched samples, which leads to the formation of hexavalent chromium, $\mathrm{Cr}^{6+}$.

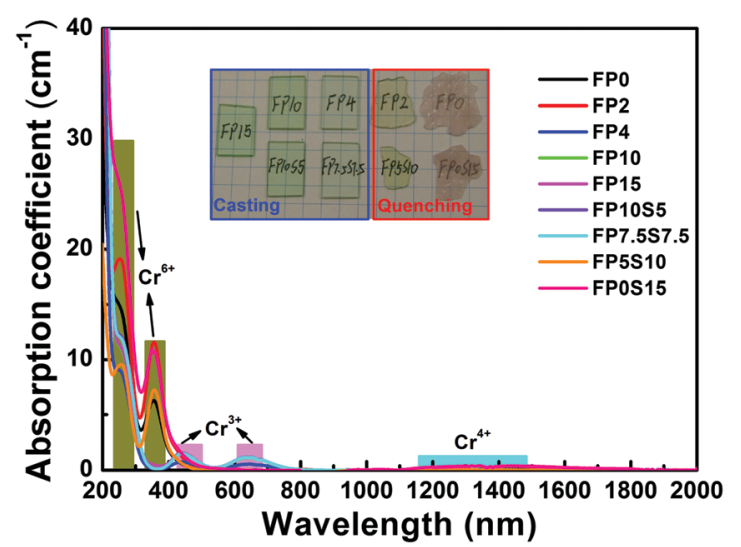

Fig. 1 Optical absorption spectra of chromium-doped FP and FPS glasses. The inset shows sample photographs (mesh spacing of $5 \mathrm{~mm}$ ).

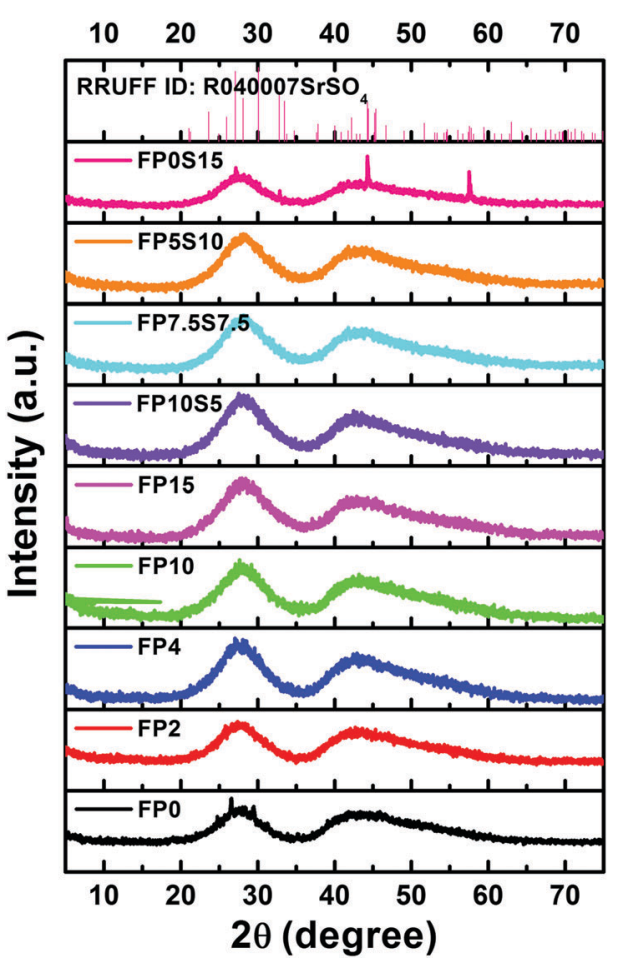

Fig. 2 XRD patterns of the chromium doped FP and FPS samples.

Noteworthily, further absorption peaks which could be characteristic of $\mathrm{Cr}^{4+}$ (in the spectral range of 1000-2000 $\mathrm{nm}$ ) are detected in the quenched samples.

XRD was employed to verify the phase assembly of all samples. Diffraction patterns are shown in Fig. 2. For all samples, data are dominated by two broad, amorphous humps which reflect the glassy state. With the exceptions of FP0 and FP0S15, there are no sharp peaks which would indicate the presence of a secondary, crystalline phase. In the latter two samples, such peaks are present, that is, they are at least partially crystallized (what is in accordance with the previous optical inspection). Using Scherer's equation, a crystallite size of $\sim 30-50 \mathrm{~nm}$ is approximated from the width of those diffraction peaks. Assignment to one or more specific crystallite phases is presently not possible due to the apparently low crystallite volume fraction and the unavailability of unambiguous reference data. Tentatively, a Celestine-type phase is identified in FP0S15, $\mathrm{SrSO}_{4}$. For FP0, we expect one or more alkaline earth fluoride phases. Here, we speculate that the crystallite species comprise fluoride (FP0 and FP0S15) and sulfide compounds (FP0S15), subject to future analysis of the specific crystallization mechanism. The low crystallite size, high sample transparency and apparent internal nucleation suggest further exploration of corresponding glass ceramics, however, beyond the scope of the present study.

The selected physical properties of the two glass series are summarized in Table 1. Upon increasing the content of phosphate, the density of the present glasses continuously increases, i.e., from $3.454 \mathrm{~g} \mathrm{~cm}^{-3}$ to $3.503 \mathrm{~g} \mathrm{~cm}^{-3}$. When $\mathrm{Sr}\left(\mathrm{PO}_{3}\right)_{2}$ is replaced by $\mathrm{SrSO}_{4}$, the density monotonically increases. 
Table 1 Physical properties of FP and FPS glasses

\begin{tabular}{|c|c|c|c|c|c|c|c|c|c|c|c|c|c|c|}
\hline \multirow[b]{2}{*}{ Glass } & \multirow{2}{*}{$\begin{array}{l}\text { Density } \\
\left(\mathrm{g} \mathrm{cm}^{-3}\right)\end{array}$} & \multicolumn{5}{|c|}{$\underline{\text { Refractive index }( \pm 0.0005)}$} & \multirow{2}{*}{$\begin{array}{l}\text { Abbe's } \\
\text { number }\end{array}$} & \multicolumn{3}{|c|}{$\begin{array}{l}\text { Thermal } \\
\text { parameters }\end{array}$} & \multirow{2}{*}{$\begin{array}{l}\text { Cutoff } \\
\text { wavelength } \\
(\mathrm{nm})\end{array}$} & \multirow{2}{*}{$\begin{array}{l}\text { Urbach } \\
\text { energy } \\
(\mathrm{eV})\end{array}$} & \multirow{2}{*}{$\Lambda$ th } & \multirow{2}{*}{$\begin{array}{l}\text { Elastic } \\
\text { modulus } \\
(\mathrm{GPa})\end{array}$} \\
\hline & & $n_{\mathrm{C}^{\prime}}(643.84)$ & $n_{\mathrm{d}}(587.56)$ & $n_{\mathrm{e}}(546.06)$ & $n_{\mathrm{F}^{\prime}}(479.98)$ & $n_{\mathrm{h}}(435.84)$ & & $T_{\mathrm{g}}$ & $T_{\mathrm{x}}$ & $T_{\mathrm{p}}$ & & & & \\
\hline FP0 & 3.454 & - & - & - & - & - & - & 403 & 460 & 475 & - & - & 0.349 & - \\
\hline FP2 & 3.472 & - & - & - & - & - & - & 421 & 498 & 514 & 395 & 1.31 & 0.356 & - \\
\hline FP4 & 3.457 & - & - & - & - & - & - & 427 & 523 & 541 & 282 & 2.87 & 0.374 & $73.1 \pm 0.6$ \\
\hline FP10 & 3.427 & 1.4638 & 1.4652 & 1.4663 & 1.4690 & 1.4714 & $89.8 \pm 17.3$ & 445 & - & - & 294 & 3.57 & 0.390 & $76.3 \pm 0.7$ \\
\hline FP15 & 3.503 & 1.4896 & 1.4911 & 1.4925 & 1.4956 & 1.4985 & $81.9 \pm 6.8$ & 467 & - & - & 292 & 3.23 & 0.432 & $77.4 \pm 0.7$ \\
\hline FP10S5 & 3.527 & 1.4801 & 1.4816 & 1.4829 & 1.4871 & 1.4884 & $69.5 \pm 5.0$ & 448 & - & - & 296 & 3.59 & 0.388 & $75.4 \pm 0.7$ \\
\hline FP7.5S7.5 & 3.531 & 1.4726 & 1.4740 & 1.4753 & 1.4781 & 1.4808 & $86.1 \pm 7.8$ & 438 & - & - & 286 & 3.59 & 0.387 & $73.4 \pm 0.7$ \\
\hline FP5S10 & 3.540 & - & - & - & - & - & & 425 & 558 & 584 & 398 & 1.19 & 0.386 & - \\
\hline FP0S15 & 3.544 & - & - & - & - & - & & 387 & 465 & 468 & - & - & 0.383 & - \\
\hline
\end{tabular}

All glasses exhibit comparably low refractive indices, in the range of 1.46-1.49, with Abbe's numbers within 69-89, that is, in the region between phosphate and fluoride-crown. Shifting from FP to FPS results in a slightly decreasing refractive index and decreasing Abbe's number.

For material processing and, for example, drawing of optical fibers, the thermal properties of the melt are of fundamental importance. The glass thermal stability is typically estimated from the characteristic temperatures, i.e., the glass transition temperature $T_{\mathrm{g}}$, the onset-temperature of crystallization $T_{\mathrm{x}}$, and the temperature of the crystallization peak as found in a DTA scan, $T_{\mathrm{p}}$ (often associated with the maximum crystallization rate). The parameter of $\Delta T=T_{\mathrm{x}}-T_{\mathrm{g}}$ is then taken as the most accessible measure of glass stability, describing the temperature interval within which the super-cooled glass melt can be processed without the risk of immediate crystallization. A value of $\Delta T$ above $100 \mathrm{~K}$ is typically taken as an indicator of relative thermal stability such as required, e.g., in a fiber drawing process. Fig. 3 displays the DTA curves of the present glasses from which the values of $T_{\mathrm{g}}, T_{\mathrm{x}}$ and $T_{\mathrm{p}}$ were extracted (Table 1). For FP0, FP2, and FP0S15, $\Delta T$ is notably below $100 \mathrm{~K}$, reflecting their previously observed tendency to crystallize (Experimental section). Similarly, also FP4 only narrowly reaches a $\Delta T$ of around $100 \mathrm{~K}$. When sulfate is added to this composition such as in FP5S10, the glass

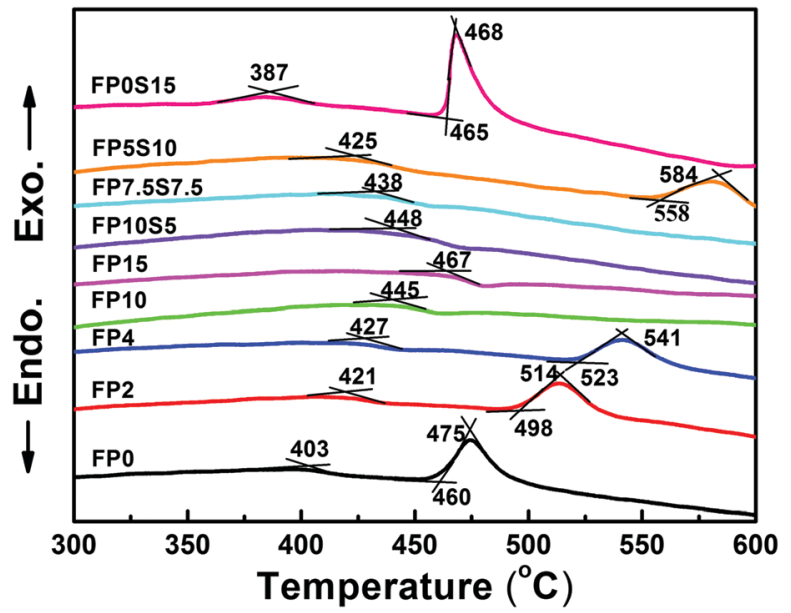

Fig. 3 Differential thermal analyses across the $T_{\mathrm{g}}$ region of FP and FPS glasses and melts. stability is significantly enhanced. Beyond that, very high stability was found for melts with phosphate above $10 \mathrm{~mol} \%$ and/or sulfate at or below $7.5 \mathrm{~mol} \%$, in which the crystallization peak could not be observed anymore in the employed experimental setting. $T_{\mathrm{g}}$ of the glasses increases significantly from $403{ }^{\circ} \mathrm{C}$ to $467{ }^{\circ} \mathrm{C}$ with increasing phosphate content, but decreases to $387^{\circ} \mathrm{C}$ with the addition of sulfate. This reflects the more covalent character of bonding among the phosphate groups relative to the ionic sulfate units, which are only weakly crosslinked by the cations. In particular, this shows a significant reduction of the melting temperature while maintaining the stability of the sulfate-free glasses.

All physical properties considered here, including glass density, refractive index, transition temperature, crystallization onset temperature, and elastic constants, are directly related to the substitution ratio between phosphate and sulfate.

For doping with transition metal elements, the local chemical properties of the matrix and, in particular, the anionic environment of the dopant are determining factors. The ability of cations to donate an electron is often approximated through mean-field approaches such as the concept of optical basicity $\Lambda_{\mathrm{th}}$. The value of $\Lambda_{\mathrm{th}}$ is approximated from the weighted sum of the molar contributions of each component, ${ }^{40}$

$$
\begin{aligned}
\Lambda_{\mathrm{th}}= & X\left(\mathrm{MgF}_{2}\right) \Lambda\left(\mathrm{MgF}_{2}\right)+X\left(\mathrm{CaF}_{2}\right) \Lambda\left(\mathrm{CaF}_{2}\right)+X\left(\mathrm{SrF}_{2}\right) \Lambda\left(\mathrm{SrF}_{2}\right) \\
& +X\left(\mathrm{AlF}_{3}\right) \Lambda\left(\mathrm{AlF}_{3}\right)+X\left(\mathrm{Sr}_{3}\left(\mathrm{PO}_{3}\right)_{2}\right) \Lambda\left(\mathrm{Sr}\left(\mathrm{PO}_{3}\right)_{2}\right) \\
& +X\left(\mathrm{SrSO}_{4}\right) \Lambda\left(\mathrm{SrSO}_{4}\right)
\end{aligned}
$$

where $X(\mathrm{i})$ is the molar fraction of component " $\mathrm{i}$ " and $\Lambda(\mathrm{i})$ is its partial molar optical basicity. In FP glass, with an increase of phosphate content, the optical basicity of the glass increases gradually. Forming FPS by adding sulfate leads to a subsequent decrease in $\Lambda_{\mathrm{th}}$. Data are summarized in Table 1.

\subsection{Structural consideration}

A structural model of FP glasses has been formulated on the basis of the ionic fluoride network into which orthophosphate $\left(Q^{0}\right)$ and pyrophosphate $\left(Q^{1}\right)$ groups are incorporated. ${ }^{41}$ It has been deducted that preferential over the formation of P-F bonds, the fluorine anion associates with the $\mathrm{Al}^{3+}$ cation to form Al-F bonds. This leads to the formation of mixed chains of $\mathrm{Al}(\mathrm{O}, \mathrm{F})_{6}$ and $\mathrm{PO}_{4}$ tetrahedra. $\mathrm{FP}$ glasses thus present a transition from an ionic fluoride ensemble to the polymer-like phosphate 

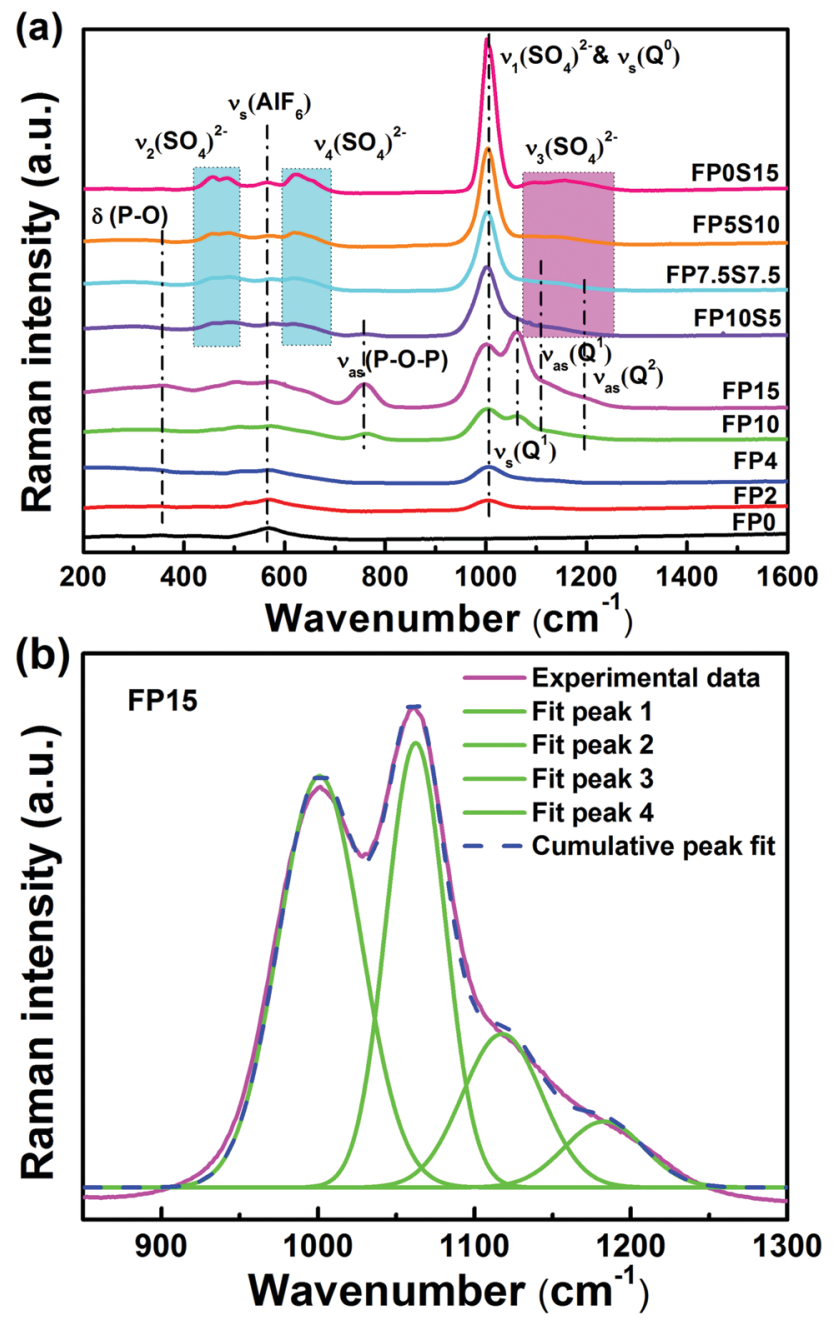

Fig. 4 (a) Raman spectra of the FP and FPS glasses and (b) example of Gaussian deconvolution on FP15 (see the text for assignment details).

network. When additional sulfate groups are introduced, the glass structure becomes more complex. In Fig. 4, Raman spectra of some FP and FPS glasses are shown to illustrate this argument. Bands were assigned on the basis of ref. 42 . In addition, the broad signal at $568 \mathrm{~cm}^{-1}$ (in FP0) is attributed to the symmetric stretching vibration of the $\mathrm{AlF}_{6}$ octahedron. ${ }^{40}$ With an increase of phosphate content and a decrease of aluminum fluoride content, this peak becomes weaker and broadens due to the formation of $\mathrm{Al}(\mathrm{F}, \mathrm{O})_{6}$ octahedra, thereby increasing the overlap with the bending vibrations of phosphate groups in the low frequency range. In brief, on the FP series, the expected gradual increase in network polymerization is clearly seen with the increase of $Q^{1}$ and $Q^{2}$ - related contributions to the vibrational spectrum (i.e., increasing fraction of bridging oxygen species). Exemplary deconvolutions of the spectral region of $850-1300 \mathrm{~cm}^{-1}$ are shown for FP15 in Fig. 4(b). That is, this broad Raman band is best fitted by four Gaussian functions with peaks at $1001 \mathrm{~cm}^{-1}$, $1062 \mathrm{~cm}^{-1}, 1109 \mathrm{~cm}^{-1}$, and $1194 \mathrm{~cm}^{-1}$. These correspond to the symmetric and asymmetric stretching modes $v_{\mathrm{s}}\left(Q^{0}\right), v_{\mathrm{s} / \mathrm{as}}\left(Q^{1}\right)$ and $v_{\text {as }}\left(Q^{2}\right)$, respectively. Sulfate for phosphate substitution leads to bands evolving around $470 \mathrm{~cm}^{-1}, 624 \mathrm{~cm}^{-1}, 1000 \mathrm{~cm}^{-1}$ and $1157 \mathrm{~cm}^{-1}$, assigned to $v_{2}\left(\mathrm{SO}_{4}\right)^{2-}, v_{4}\left(\mathrm{SO}_{4}\right)^{2-}, v_{1}\left(\mathrm{SO}_{4}\right)^{2-}$ and $v_{3}\left(\mathrm{SO}_{4}\right)^{2-} \cdot 22,25$ Noteworthily, no Raman signal could be detected in the spectral region around $840-850 \mathrm{~cm}^{-1}$, which would indicate the presence of P-F bonding. ${ }^{40}$ In addition, it can be seen that the maximum phonon energy of the present glass increases from $1001 \mathrm{~cm}^{-1}$ to $1157 \mathrm{~cm}^{-1}$. A lower phonon energy can increase the radiative transition probability of ions.

\subsection{Luminescence properties and crystal field parameters}

Photoluminescence (PL) spectra of Cr-doped FP and FPS glasses are shown in Fig. 5. A broad emission band centered at $734 \mathrm{~nm}$ is observed in cast glasses, resulting from the spin-allowed ${ }^{4} \mathrm{~T}_{2} \rightarrow{ }^{4} \mathrm{~A}_{2}$ transition in $\mathrm{Cr}^{3+} \cdot{ }^{12,13,15}$ Differing from this, a very intense emission band is detected in the quenched samples of FP0 and FP0S15 at $\sim 694 \mathrm{~nm}$ (corresponding to the $R$-line). This band originates from the spin-forbidden transition of $\mathrm{Cr}^{3+}:{ }^{2} \mathrm{E} \rightarrow{ }^{4} \mathrm{~A}_{2}$. The accompanying broader background emission $(700-900 \mathrm{~nm})$ is attributed to the phonon sidebands of the ${ }^{4} \mathrm{~T}_{2} \rightarrow{ }^{4} \mathrm{~A}_{2}$ transition. There is a positive correlation between the emission intensity and optical basicity. As the glass optical basicity increases with increasing phosphate content, also the emission intensity gradually increases. Similar behaviour was found in chromium-doped silicate glasses. ${ }^{43}$ Noteworthily, potential interference through the effect of "photon trapping", on luminescence spectra and decay times is negligible because the samples used for spectroscopic tests are very thin. This is further confirmed by comparing the spectroscopic characteristics for different sample sizes (see Fig. S2 in the ESI $\dagger$ ). Noteworthily, the full width at half maximum (FWHM) of the sharp peak at $694 \mathrm{~nm}$ is about $83 \mathrm{~nm}$, which is much broader than what is typically observed in $\mathrm{Cr}^{3+}$-doped crystals or glass ceramics. ${ }^{44}$ The inhomogeneous broadening of the $R$ line reflects the higher versatility of states which is available for $\mathrm{Cr}^{3+}$ precipitation, where each individual state provides slight differences in crystal-field splitting. ${ }^{45,46}$ Besides the $\mathrm{Cr}^{3+}$ ion, also other chromium species exhibit red photoemission in some glasses. For example, Herren et al. observed a red emission at $\sim 671 \mathrm{~nm}\left(14900 \mathrm{~cm}^{-1}\right)$ in Cr-doped silica glass

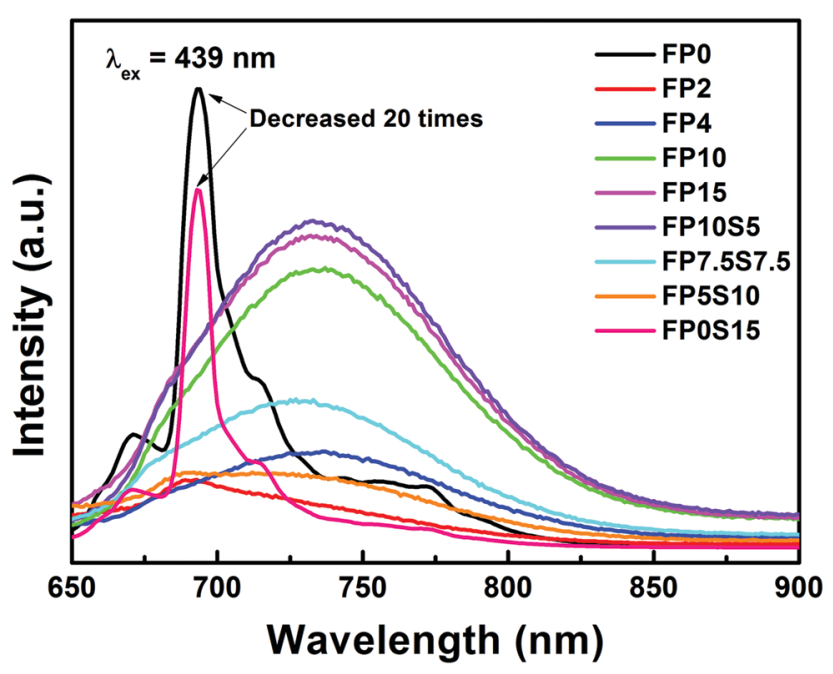

Fig. $5 \mathrm{PL}$ spectra of FP and FPS glasses doped with 0.05 mol\% $\mathrm{Cr}_{2} \mathrm{O}_{3}$. 
which was prepared through a sol-gel method. They ascribed their observation to the presence of $\mathrm{Cr}^{5+}$ ions. ${ }^{47}$ Later, the same authors specified this interpretation with a new assignment, i.e., to the ligand-metal charge transfer (LMCT) transitions of $\mathrm{Cr}^{6+}$ ions. ${ }^{48,49}$ They also ascribed the red band of chromium-doped sol-gel silica glass to $\mathrm{Cr}^{6+}$ ions being associated with $\mathrm{Cr}^{3+}, \mathrm{Cr}^{4+}$ and $\mathrm{Cr}^{5+}$ centers. $^{50}$ Strk et al. obtained a red emission at $655 \mathrm{~nm}$ in Cr-doped silica sol-gel glasses (with excitation bands at $280 \mathrm{~nm}$, $400 \mathrm{~nm}$, and $500 \mathrm{~nm}){ }^{51}$ Assisted through electron paramagnetic resonance spectroscopy, they proposed a charge-compensation mechanism and attributed the emission band to pairs of $\mathrm{Cr}^{6+}$ and $\mathrm{Cr}^{5+}$ ions. Clearly, both observations indicate the complexity in assigning the red emission band to either $\mathrm{Cr}^{3+}$ or $\mathrm{Cr}^{6+}$, without a final resolution at this point.

Photoluminescence excitation (PLE) spectra of the representative FP10S5 and FP0 glasses are provided in Fig. 6. Monitoring the emission at $734 \mathrm{~nm}$ in FP10S5, a continuous envelope with individual bands centered at $287 \mathrm{~nm}, 425 \mathrm{~nm}$, and $600 \mathrm{~nm}$ is observed, originating from the ${ }^{4} \mathrm{~A}_{2} \rightarrow{ }^{4} \mathrm{~T}_{1}\left({ }^{4} \mathrm{P}\right)$, ${ }^{4} \mathrm{~A}_{2} \rightarrow{ }^{4} \mathrm{~T}_{1}\left({ }^{4} \mathrm{~F}\right)$, and ${ }^{4} \mathrm{~A}_{2} \rightarrow{ }^{4} \mathrm{~T}_{2}\left({ }^{4} \mathrm{~F}\right)$ transitions of $\mathrm{Cr}^{3+}$, respectively. ${ }^{44}$ The PLE spectra of the other cast samples are similar to this. Noteworthily, the excitation peaks occur at somewhat shorter wavelengths as compared with the absorption spectra. This signifies that the low-field $\mathrm{Cr}^{3+}$ ions have lower luminescence efficiency. ${ }^{52}$ Another important point is that the emission position and intensity show high correlations with the excitation wavelength, which moves to a higher wavelength (e.g., from $648 \mathrm{~nm}$ to $734 \mathrm{~nm}$ ) upon increasing the excitation wavelength (from $287 \mathrm{~nm}$ to $600 \mathrm{~nm}$ ). Also for FP0, the PLE spectrum (monitored at $694 \mathrm{~nm}$ emission) consists of three broad excitation bands, here at $260 \mathrm{~nm}, 404 \mathrm{~nm}$, and $540 \mathrm{~nm}$, corresponding to the same transitions as above. The blue-shift relative to FPS is due to a stronger crystal field surrounding the chromium ions. Upon excitation at either of the three peak wavelengths, the position of the emission spectra remains unchanged except for the difference in intensity. An interesting point is that the emission spectra now narrow-down to a sharp line at $694 \mathrm{~nm}$ with a FWHM of only $4 \mathrm{~nm}$, largely because of the inhomogeneous distribution of microcrystals in the quenched samples of FP0 and FP0S15.

Fig. 7 depicts the luminescence decay curves of the cast and quenched samples. The observed emission dynamics clearly deviate from a double-exponential decay function, which is taken as a result of multi-site distribution or interaction among $\mathrm{Cr}^{3+}$ species in the glass. ${ }^{45}$ The average lifetime of the $734 \mathrm{~nm}$ emission in cast samples lies within $39.7 \mu \mathrm{s}$ to $34.5 \mu \mathrm{s}$. This is much higher than what has previously been observed on $\mathrm{Cr}^{3+}$ doped phosphate glass $(15 \mu \mathrm{s}) .{ }^{12}$ For the quenched samples of FP2 and FP5S10, the lifetimes of the sharp emission band at $694 \mathrm{~nm}$ reach about $311 \mu \mathrm{s}$ and $74.5 \mu \mathrm{s}$, respectively. In FP0 and FP0S15, they increase further to $\sim 1.06 \mathrm{~ms}$ and $1.07 \mathrm{~ms}$, respectively, but are still somewhat lower than in $\mathrm{Cr}^{3+}$-doped silicate glass ceramics $(2.45 \mathrm{~ms}) .{ }^{44}$ The latter observation clearly confirms that in the quenched samples, $\mathrm{Cr}^{3+}$ precipitates in a crystalline environment.

The Tanabe-Sugano diagram is frequently used to analyze the energy level scheme of $\mathrm{Cr}^{3+}\left([\mathrm{Ar}] 3 \mathrm{~d}^{3}\right)$. For this, crystal field parameter $D_{\mathrm{q}}$ and Racah parameter $B$ can be estimated according to ${ }^{53}$

$$
\begin{gathered}
D_{\mathrm{q}}=\frac{E\left({ }^{4} \mathrm{~A}_{2} \rightarrow{ }^{4} \mathrm{~T}_{2}\right)}{10} \\
\frac{D_{\mathrm{q}}}{B}=\frac{15(m-8)}{\left(m^{2}-10 m\right)} \\
m=\frac{E\left({ }^{4} \mathrm{~A}_{2} \rightarrow{ }^{4} \mathrm{~T}_{1}\right)-E\left({ }^{4} \mathrm{~A}_{2} \rightarrow{ }^{4} \mathrm{~T}_{2}\right)}{D_{\mathrm{q}}}
\end{gathered}
$$

where $m$ is determined from the resonance energy of the ${ }^{4} \mathrm{~A}_{2} \rightarrow{ }^{4} \mathrm{~T}_{1}$ and ${ }^{4} \mathrm{~A}_{2} \rightarrow{ }^{4} \mathrm{~T}_{2}$ transitions. Generally, the region of intermediate octahedral fields, $2.1<D_{\mathrm{q}} / B<2.3$, was defined to separate the low-field and high-field regions. ${ }^{54}$ In the cast glasses, the $D_{\mathrm{q}}, B$, and $D_{\mathrm{q}} / B$ values are around $1560 \mathrm{~cm}^{-1}$, $760 \mathrm{~cm}^{-1}$ and 2.1 , respectively, whereas in the quenched samples,
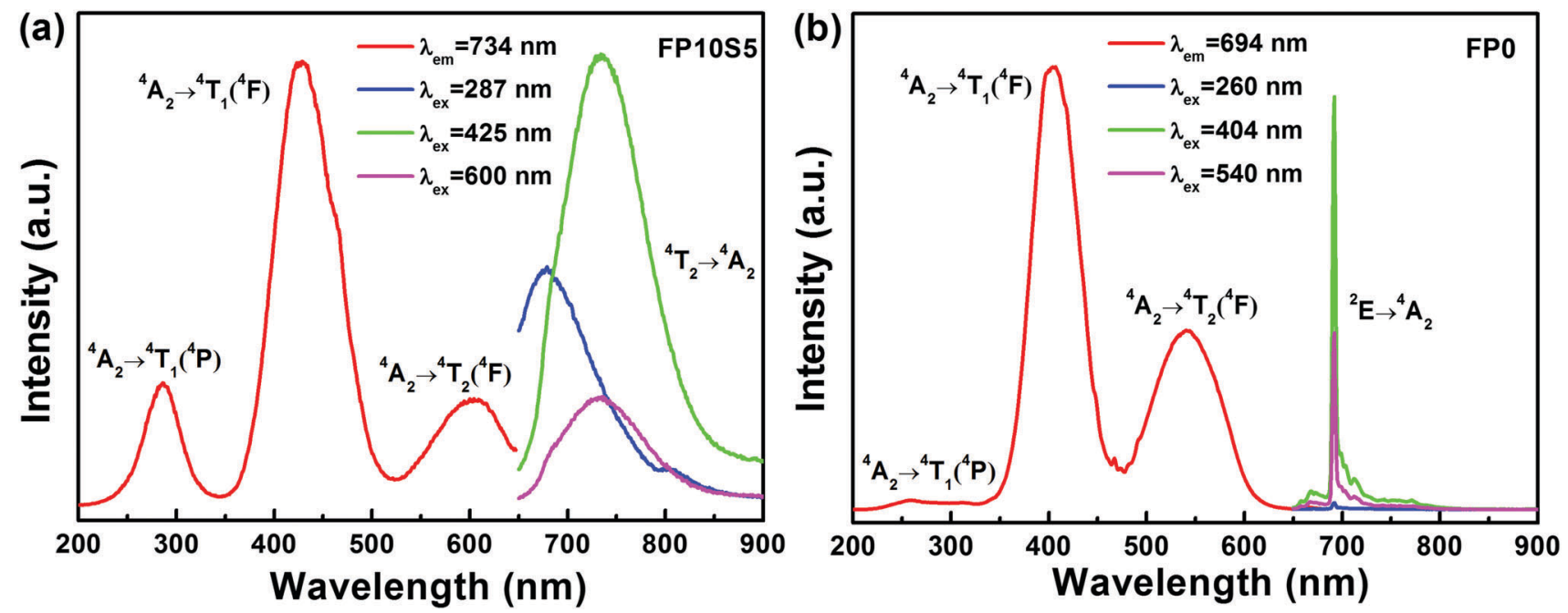

Fig. 6 PLE and PL spectra of selected (a) FP10S5 and (b) FPO glasses doped with 0.05 mol\% $\mathrm{Cr}_{2} \mathrm{O}_{3}$. 

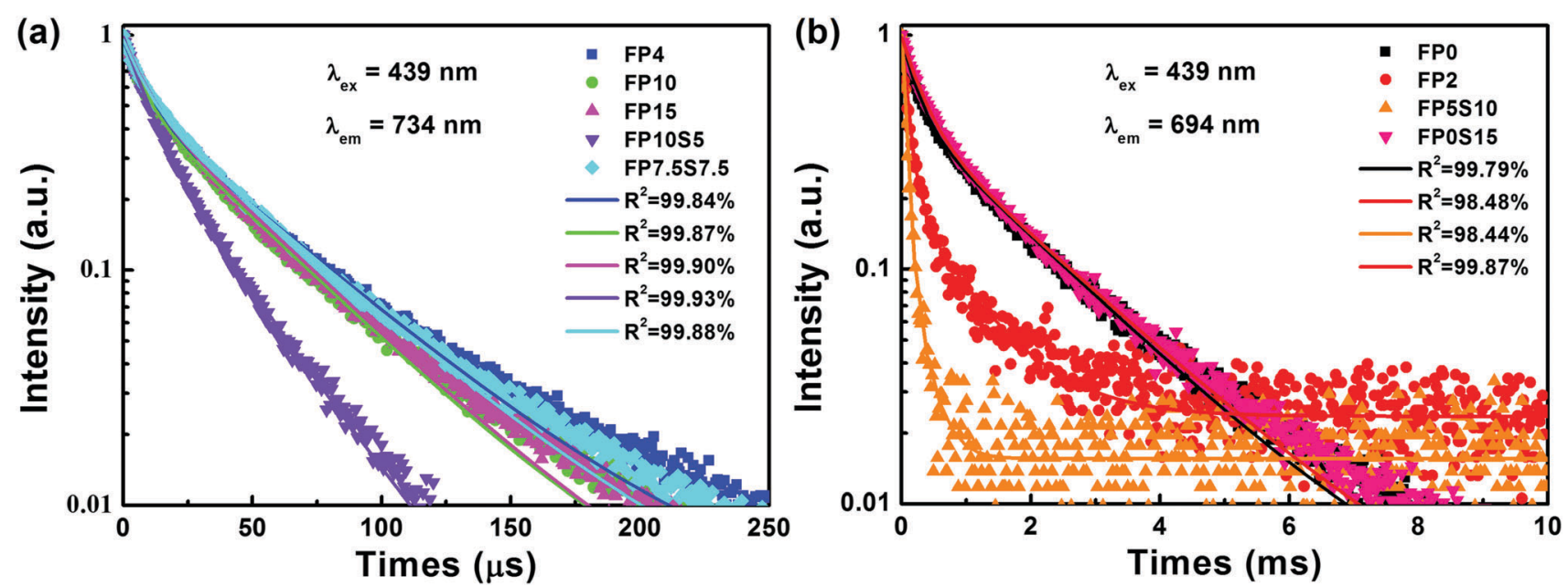

Fig. 7 Luminescence decay curves of $\mathrm{Cr}^{3+}$-doped (a) casting samples and (b) quenching samples.

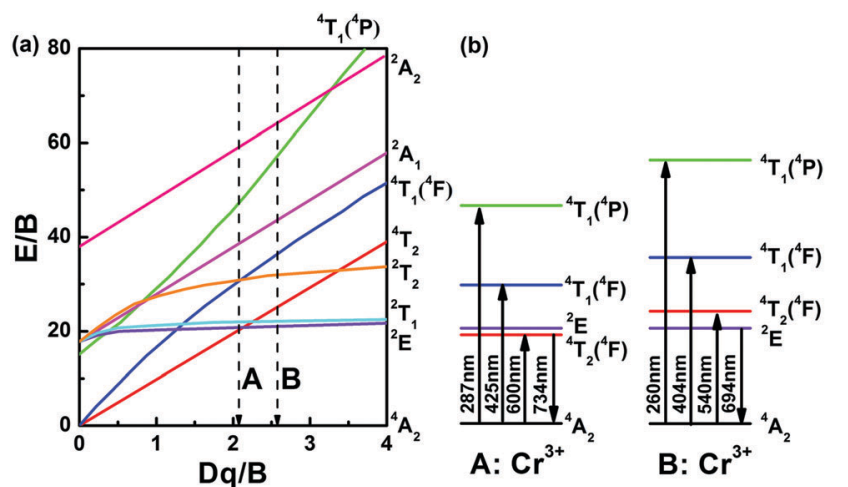

Fig. 8 (a) Tanabe-Sugano diagram and (b) energy level diagram of $\mathrm{Cr}^{3+}$-doped FP and FPS glasses. Labels A and B represent the position of calculated $D_{\mathrm{q}} / B$ in FP10S5 and FPO samples, respectively.

the values were found to be $1640 \mathrm{~cm}^{-1}, 630 \mathrm{~cm}^{-1}$ and 2.6 . This means that the crystal field changes from a low-field to a high-field configuration as a result of varying glass compositions and quenching. We denote the two different situations as (A) and (B), as shown in Fig. 8. As can be readily seen, the ${ }^{4} T_{2}$ state is very sensitive to $D_{\mathrm{q}} / B$ while the ${ }^{2} \mathrm{E}$ state is just the opposite. In situation (A), the $\mathrm{Cr}^{3+}$ ion locates in a lower ligand field environment, so the ${ }^{4} \mathrm{~T}_{2}$ level is lower than the ${ }^{2} \mathrm{E}$ level, which results in broadband emission arising from the spin-allowed ${ }^{4} \mathrm{~T}_{2} \rightarrow{ }^{4} \mathrm{~A}_{2}$ transition. In contrast, when the $\mathrm{Cr}^{3+}$ ions locate in the high crystal field (situation (B)), the ${ }^{2} \mathrm{E}$ level falls below the ${ }^{4} \mathrm{~T}_{2}$ level and, thus, the spectra exhibit a sharp $R$-line originating from the spin-forbidden ${ }^{2} \mathrm{E} \rightarrow{ }^{4} \mathrm{~A}_{2}$ transition.

\section{Conclusions}

In summary, we reported on unusually stable multi-anion glasses of the fluoride-sulfophosphate type (FPS) as a new host material for optically active cation species. Despite a notoriously low polymerization grade, anion mixing in this glass system enables the facile manufacture of bulk or fiber devices which combine several advantages of fluoride and phosphate glasses while using the stabilizing effect of sulfate added. Using the example of chromium doping, we demonstrate a broad red photoluminescence at $734 \mathrm{~nm}$ and an inhomogeneous broadening of the $R$-line at $694 \mathrm{~nm}$, originating from the ${ }^{4} \mathrm{~T}_{2} \rightarrow{ }^{4} \mathrm{~A}_{2}$ and ${ }^{2} \mathrm{E} \rightarrow{ }^{4} \mathrm{~A}_{2}$ transitions of $\mathrm{Cr}^{3+}$, respectively. The luminescence mechanism was further analyzed on the basis of the corresponding Tanabe-Sugano diagram. Tailored through chemical composition, internally nucleated precipitation of a nanocrystalline fluoride phase enables switching between high-field and low-field configurations of the $\mathrm{Cr}^{3+}$ ion, resulting in the specific emission properties and setting the path towards FPS-based optical devices, in particular, broadband tunable fiber amplifiers and lasers.

\section{Acknowledgements}

This project has received funding from the European Research Council (ERC) under the European Union's Horizon 2020 research and innovation programme (ERC grant UTOPES, grant agreement no. 681652). W. C. Wang gratefully acknowledges the Chinese Scholarship Council for personal support. We thank our colleagues C. Zeidler, N. Buchert, S. Fuhrmann, C. Siedler and Y. Ding for help with sample preparation and data acquisition.

\section{References}

1 G. Boulon, Opt. Mater., 2012, 34, 499.

2 M. Yasin, S. W. Harun and H. Arof, Selected Topics on Optical Fiber Technology, InTech, 2012.

3 T. H. Maiman, Nature, 1960, 187, 493.

4 C. R. Pollock, D. B. Barber, J. L. Mass and S. Markgraf, IEEE J. Sel. Top. Quantum Electron., 1995, 1, 62.

5 S. B. Mirov, V. V. Fedorov, I. S. Moskalev and D. V. Martyshkin, IEEE J. Sel. Top. Quantum Electron., 2007, 13, 810 . 
6 M. Mond, D. Albrecht, E. Heumann, G. Heumann, G. Huber and S. Kück, Opt. Lett., 2002, 27, 1034.

7 J. C. Chen, Y. S. Lin, C. N. Tsai, K. Y. Huang, C. C. Lai, W. Z. Su, R. C. Shr, F. J. Kao and T. Y. Chang, IEEE Photonics Technol. Lett., 2007, 19, 595.

8 D. G. Deng, H. P. Ma, S. Q. Xu, Q. Wang, L. H. Huang, S. L. Zhao, H. P. Wang and C. X. Li, J. Opt. Soc. Am. B, 2010, 27, 1659.

9 U. R. Rodríguez-Mendoza, V. Lavín, I. R. Martín and V. D. Rodríguez, J. Lumin., 2004, 106, 77.

10 H. R. Verdun, L. M. Thomas, D. M. Andrauskas, T. McCollum and A. Pinto, Appl. Phys. Lett., 1988, 53, 2593.

11 C. Deka, M. Bass, B. H. T. Chai and Y. Shimony, J. Opt. Soc. Am. B, 1993, 10, 1499.

12 E. J. Sharp, J. E. Miller and M. J. Weber, Phys. Lett. A, 1969, 30, 142.

13 T. Murata, M. Torisaka, H. Takebe and K. Morinaga, J. Non-Cryst. Solids, 1997, 220, 139.

14 S. M. Yeh, S. L. Huang, Y. J. Chiu, H. Taga, P. L. Huang, Y. C. Huang, Y. K. Lu, J. P. Wu, W. L. Wang, D. M. Kong, K. Y. Huang, J. S. Wang, P. Yeh and W. H. Cheng, J. Lightwave Technol., 2012, 30, 921.

15 Z. J. Fang, S. P. Zheng, W. C. Peng, H. Zhang, Z. J. Ma, S. F. Zhou, D. P. Chen and J. R. Qiu, J. Am. Ceram. Soc., 2015, 98, 2772.

16 M. J. Weber, J. Non-Cryst. Solids, 1990, 123, 208.

17 J. H. Campbell and T. I. Suratwala, J. Non-Cryst. Solids, 2000, 263, 318.

18 S. Tanabe, C. R. Chim., 2002, 5, 815.

19 K. Griebenow, U. Hoppe, D. Möncke, E. I. Kamitsosc and L. Wondraczek, J. Non-Cryst. Solids, 2017, 460, 136.

20 B. P. Rodrigues, J. Deubener and L. Wondraczek, Front. Mater., 2016, 3, 25.

21 K. Griebenow, E. I. Kamitsos and L. Wondraczek, J. Non-Cryst. Solids, 2017, 468, 74.

22 N. Da, O. Grassmé, K. H. Nielsen, G. Peters and L. Wondraczek, J. Non-Cryst. Solids, 2011, 357, 2202.

23 N. Da, S. Krolikowski, K. H. Nielsen, J. Kaschta and L. Wondraczek, J. Am. Ceram. Soc., 2010, 93, 2171.

24 S. Sirotkin, R. Meszaros and L. Wondraczek, Int. J. Appl. Glass Sci., 2012, 3, 44.

25 D. Möncke, S. Sirotkin, E. Stavrou, E. I. Kamitsos and L. Wondraczek, J. Chem. Phys., 2014, 141, 224509.

26 S. Reibstein, N. Da, J. P. Simon, E. Spiecker and L. Wondraczek, Phys. Chem. Glasses, 2012, 53, 61.

27 D. Ehrt and T. Töpfer, Proc. SPIE, 2000, 4102, 95.

28 J. F. Philipps, T. Töpfer, H. Ebendorff-Heidepriem, D. Ehrt and R. Sauerbrey, Appl. Phys. B: Lasers Opt., 2001, 72, 399.

29 H. Ebendorff-Heidepriem, D. Ehrt, M. Bettinelli and A. Speghini, J. Non-Cryst. Solids, 1998, 240, 66.
30 S. Tanabe, S. Yoshii, K. Hirao and N. Soga, Phys. Rev. B, 1992, 45, 4620.

31 J. J. Zhang, D. B. He, Z. C. Duan, L. Y. Zhang, S. X. Dai and L. L. Hu, Laser \& Optronics Prog., 2005, 42, 12.

32 L. Y. Zhang, L. Wen, H. T. Sun, J. J. Zhang and L. L. Hu, J. Alloys Compd., 2005, 391, 156.

33 P. Ebeling, D. Ehrt and M. Friedrich, Phosphorus Res. Bull., 1999, 10, 484.

34 G. A. Kumar, A. Martinez and E. De la Rosa, J. Lumin., 2002, 99, 141.

35 G. A. Kumar, E. De la Rosa, A. Martinez, N. V. Unnikrishnan and K. Ueda, J. Phys. Chem. Solids, 2003, 64, 69.

36 Q. H. Le, D. Möncke, E. I. Kamitsos and L. Wondraczek, Society of Glass Technology (SGT) Centenary Conference, 2016.

37 S. Emura, H. Maeda, Y. Kuroda and T. Murata, Jpn. J. Appl. Phys., 1993, 32, 734.

38 J. Ueda and S. Tanabe, J. Am. Ceram. Soc., 2010, 93, 3084.

39 W. A. Weyl, Coloured Glasses, Society of Glass Technology, 2016.

40 L. L. Velli, C. P. E. Varsamis and E. I. Kamitsos, Phys. Chem. Glasses, 2008, 49, 182.

41 D. Möncke, D. Ehrt, L. Velli, C. P. E. Varsamis and E. I. Kamitsos, Int. Congr. Glass, Proc., 20th, 2004.

42 A. Thieme, D. Möncke, R. Limbach, S. Fuhrmann, E. I. Kamitsos and L. Wondraczek, J. Non-Cryst. Solids, 2015, 410, 142.

43 H. Yamazaki and S. Tanabe, Jpn. J. Appl. Phys., 2005, 44, 5011.

44 D. Q. Chen, Z. Y. Wan and Y. Zhou, Opt. Lett., 2015, 40, 3607.

45 F. Rasheed, K. P. D'onnell, B. Henderson and D. B. Hollis, J. Phys.: Condens. Matter, 1991, 3, 1915.

46 S. V. Bulyarskii, A. E. Kozhevin, S. N. Mikov and V. V. Prikhodko, Phys. Status Solidi A, 2000, 180, 555.

47 M. Herren, H. Nishiuchi and M. Morita, J. Chem. Phys., 1994, 101, 4461.

48 M. Moirta, N. Miyazaki, S. Murakami, M. Herren and D. Rau, J. Lumin., 1998, 76\&77, 238.

49 M. Herren, K. Yamanaka and M. Morita, Tech. Rep. Seikei Univ., 1995, 32, 61.

50 M. Morita, D. Rau, S. Kajiyama, T. Sakurai, M. Baba and M. Iwamura, Mater. Sci.-Pol., 2004, 22, 5.

51 W. Stręk, P. J. Dereń, E. Łukowiak, J. Hanuza, H. Drulis, A. Bednarkiewicz and V. Gaishun, J. Non-Cryst. Solids, 2001, 288, 56.

52 A. van Die, G. Blasse and W. F. van der Weg, J. Phys. C: Solid State Phys., 1985, 18, 3379.

53 C. R. Kesavulu, R. P. S. Chakradhar, R. S. Muralidhara, J. L. Rao and R. V. Anavekar, J. Alloys Compd., 2010, 496, 75.

54 F. Rasheed, K. P. O'Donnell, B. Henderson and D. B. Hollis, J. Phys.: Condens. Matter, 1991, 3, 3825. 